\title{
Caracterização do atendimento por redes de abastecimento de água em áreas rurais do Ceará: evidências do impacto da implantação do Sistema Integrado de Saneamento Rural (SISAR)
}

\section{Characterization of the water supply systems attendance in rural areas in Ceara: evidence of the impact of the implementation of Sistema Integrado de Saneamento Rural (SISAR)

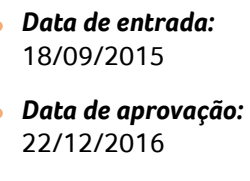 \\ Data de entrada: \\ Data de aprovação: 22/12/2016}

\section{Resumo}

O presente artigo caracteriza o acesso às redes de abastecimento de água em áreas rurais do Ceará e busca identificar evidências do impacto do Sistema Integrado de Saneamento Rural (SISAR) nesse mesmo contexto. Para tanto, esse trabalho conta com informações provenientes do banco de dados do próprio SISAR, assim como dos Censos Demográficos de 1991, 2000 e 2010. É realizada uma análise descritiva das séries históricas do IBGE e do SISAR, evidenciando-se o marco de implantação do programa. A seguir, desenvolve-se uma análise de regressão logística dos determinantes de presença de rede nos domicílios rurais do Ceará, no ano de 2010. Além de aspectos socioeconômicos e demográficos, evidencia-se que a existência do SISAR explica a presença de rede nas habitações rurais. São encontradas evidências de que o programa teve efeito positivo no que tange ao acesso à rede de abastecimento de água nas regiões rurais do Ceará. Palavras-chave: SISAR. Saneamento Rural. Abastecimento de Água.

\section{Abstract}

This paper characterizes the water supply network access in rural areas in Ceara and aims to identify evidence of the impact of Integrated Rural Sanitation (SISAR) in this context. For this purpose, this research reckons with SISAR data, as well as the 1991, 2000 and 2010 Demographic Brazilian Census. A descriptive analysis of historical series from IBGE and SISAR is performed, showing the implementation of the program, and then a logistic regression analysis of the determinants of network presence in Ceara rural households in the year of 2010 is developed. Besides the socioeconomic and demographic aspects, the presence of SISAR proved to be an explanatory variable of network presence in rural dwellings. Evidence showed that the program had a positive effect in terms of access to water network in rural regions in Ceara. Keywords: SISAR. Rural sanitation. Water supply.

Pedro Valle Salles - Graduado em Engenharia Civil pela Universidade Federal de Minas Gerais (UFMG). Cursando especialização em Engenharia de Segurança do Trabalho pela Pontifícia Universidade Católica de Minas Gerais (PUC-MG) e mestrado em Engenharia Civil pelo Centro Federal de Educação Tecnológica de Minas Gerais (CEFET-MG). E-mail: pedrovallesalles025agmail.com.

Sonaly Cristina Rezende Borges de Lima - Graduada em Engenharia Civil, com ênfase em Saneamento, pela Universidade Federal de Minas Gerais (UFMG) . Mestre em Saneamento, Meio Ambiente e Recursos Hídricos na UFMG. Doutora no Centro de Desenvolvimento e Planejamento Regional da UFMG (Cedeplar). Professora do Departamento de Engenharia Sanitária e Ambiental da UFMG.

*Endereço para correspondência: Departamento de Engenharia Civil, Prédio 18, CEFET-MG. Av. Amazonas, 7675 - Nova Gameleira, Belo Horizonte, Minas Gerais, , CEP 30510-000. Telefone: (31) 99842-2726. 


\section{INTRODUÇÃO}

A região rural do Nordeste do Brasil é, historicamente, muito afetada pela falta de investimentos públicos e, consequentemente, pela carência de serviços básicos de saneamento, dentre eles o abastecimento de água. De Acordo com Rezende; Heller (2008) e Hochman (1988), foi no início do século XX que se difundiu a necessidade de sanear os chamados Sertões do País.

Tendo em vista que problemas de gestão e planejamento agravam as mazelas advindas da seca, é possível trazer à tona os focos principais do presente artigo: o Sistema Integrado de Saneamento Rural do Ceará (SISAR-CE) e a conjuntura das áreas rurais do estado do Ceará, no que tange às formas de obtenção de água.

De acordo com o Censo Demográfico de 2010 (IBGE, 2012), em todo o Brasil, cerca de $28 \%$ dos domicílios rurais são atendidos por rede geral com canalização interna de água, sendo as redes de distribuição ampliadas rumo às comunidades rurais que adotam a gestão comunitária dos sistemas. O SISAR, programa voltado para o abastecimento de água em comunidades rurais no Estado do Ceará, vem, desde meados da década de 1990, ampliando a cobertura das redes de água nos domicílios rurais. Devido ao fato de o Brasil ser um país carente de soluções na área do saneamento rural, o SISAR pode surgir como um modelo a ser adotado em outras regiões do país, como forma de mitigar um histórico problema de saneamento.

O presente artigo objetiva investigar como se sucede a obtenção de água pelas populações rurais do Ceará e averiguar a relação entre a presença do Sistema SISAR e o aumento da cobertura de redes de água nos domicílios rurais do Estado. De posse dessas análises, é possível avaliar o desenvolvimento das ações adotadas pelo SISAR e, também, aferir se esse modelo de gestão apresenta-se como uma boa alternativa para a distribuição da água nas regiões rurais do país.
Criado em 1995, por meio de uma parceria entre a Companhia de Água e Esgoto do Ceará (Cagece) e o Banco KFW - instituição de fomento alemã -, o SISAR é voltado para a assessoria no gerenciamento dos sistemas de distribuição de água - que são assumidos pelas próprias associações das comunidades rurais -, fornecendo-lhes apoio técnico e administrativo (SPINK, 2009; MELEG, 2012). O início de seu funcionamento foi na região de Sobral, sendo que apenas em 2001 o Programa se estendeu para as demais regiões do Ceará.

As metas principais do SISAR são: i) aumento dos níveis de cobertura de abastecimento de água por rede de distribuição; ii) educação e conscientização da população sobre a importância de sua participação no Programa; iii) participação comunitária; iv) capacitação de recursos humanos, a fim de que estes sejam capazes de gerir o sistema; v) viabilidade econômica, financeira e administrativa dos sistemas (PRINCE, 1999).

A presença do SISAR nas comunidades está condicionada a uma série de aspectos: i) à disponibilidade de água; ii) às características geográficas, políticas e sociais locais; iii) à premissa de cobrança de tarifas mensais de seus usuários, que devem estar predispostos a tal conduta; iv) à adequação das práticas e do sistema local ao padrão técnico do SISAR; v) à existência de um sistema de instalações elétricas adequadas; vi) à existência de uma associação comunitária de usuários funcionando adequadamente e ao pagamento da taxa de filiação (MELEG, 2012; PRINCE, 1999).

\section{SISTEMA INTEGRADO DE SANEAMENTO RURAL DO CEARÁ}

Atualmente, o SISAR encontra-se dividido em oito sub-bacias, como ilustra a Figura 1. Essa divisão engloba todos os municípios do Estado, apesar de nem todos participarem do Programa. As datas presentes na Figura 1 representam o início das atividades em cada sub-bacia. 
Figura 1: Divisão administrativa do SISAR - CE

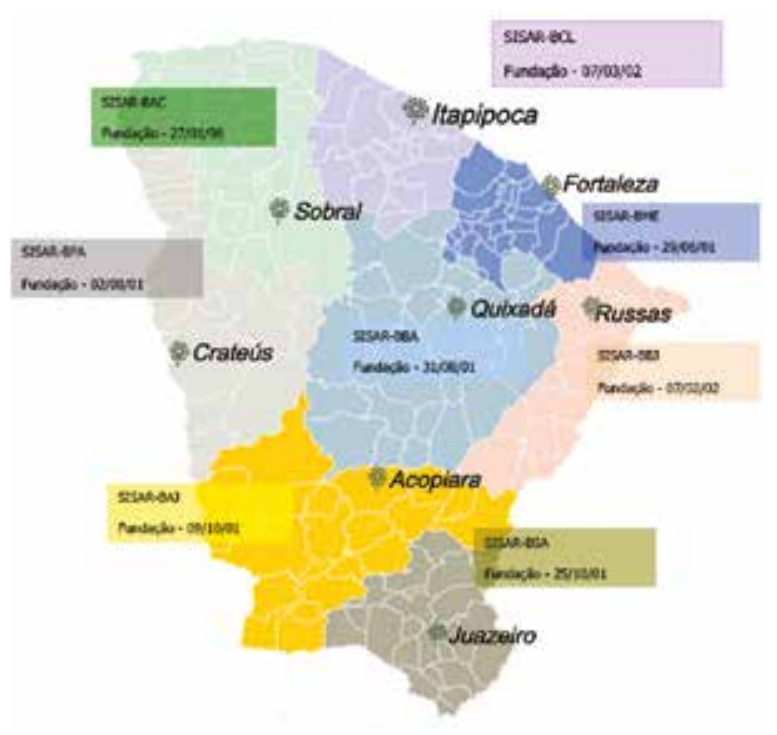

Fonte: Cagece (2009 apud MELEG, 2012).

A implantação do SISAR em uma comunidade é constituída de quatro fases principais:

- Organização Comunitária: imprescindível para a implantação do sistema. O presidente de tal associação representa a comunidade nas assembleias do SISAR (CRUZ et al., 2014; PRINCE, 1999).

- Planejamento: a verba liberada pelos órgãos de fomento é administrada pela Secretaria Estadual de Desenvolvimento Agrário (CRUZ et al., 2014; PRINCE, 1999).

- Construção dos sistemas: realizada por empresas privadas e supervisionada pela Cagece. Obras de transposição, adutoras e barragens ficam a cargo da Superintendência de Obras Hidráulicas (SOHIDRA). A cobrança e fiscalização dos recursos hídricos é de responsabilidade da Companhia de Gestão dos Recursos Hídricos (COGERH) (CRUZ et al., 2014; PRINCE, 1999).

- Operação: a ser realizada por um operadorvoluntário da localidade em questão, que deve receber treinamento para realizar pequenas manutenções e relatar problemas maiores, esses solucionados por técnicos especializados do SISAR (CRUZ et al., 2014; PRINCE, 1999).

A participação das associações comunitárias é indispensável para o funcionamento do Programa SISAR. Na assembleia geral das comunidades são escolhidos os membros dos conselhos administrativos e fiscais. Ambos os conselhos são formados por residentes das comunidades e por representantes da Cagece, do KFW, dos municípios envolvidos e da Secretaria Estadual de Infraestrutura do Ceará. O apoio técnico é provido por funcionários contratados pelo SISAR. O operador do sistema local e o pessoal voluntário são originários das comunidades participantes (SPINK, 2009). A Figura 2 apresenta a estrutura organizacional do Programa SISAR.

Figura 2: Estrutura organizacional do SISAR

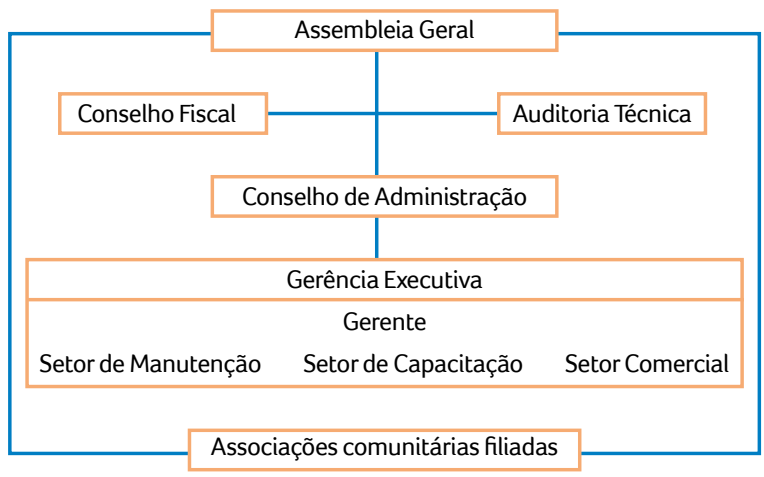

Fonte: Schweizer e Nieradtka (2001).

Um fator de destaque do Programa em relação a outros programas voltados para o saneamento é o dito empoderamento das comunidades. Empoderar incide no acréscimo da liberdade de escoIha, na possibilidade de moldar o próprio destino, o que aumenta a autoestima da população e abre novos caminhos para as comunidades. Populações historicamente desprovidas de empoderamento, quando sujeitas a essa transformação, passam a ter uma dose maior de domínio sobre 
suas vidas, tomando decisões que alteram suas histórias de acordo com especificidades locais (NARAYAN, 2002).

\section{METODOLOGIA}

Utilizaram-se dados do SISAR e dos Censos Demográficos de 1991, 2000 e 2010. O processamento desses dados foi realizado por meio de dois softwares, o Excel e o Statistical Package for the Social Sciences (SPSS). Inicialmente, os dados do IBGE relativos ao Estado do Ceará encontravamse separados em dois blocos de notas no formato txt, um com os dados referentes aos domicílios e outro às pessoas. Para leitura e organização dos mesmos foi necessária a formulação de sintaxe, onde se definiram as variáveis, bem como o tamanho e a posição por elas ocupadas. Obtiveram-se, então, dois bancos de dados, um de residências e outro de indivíduos, que posteriormente foram agrupados.

Com os bancos de dados formulados no SPSS, partiu-se para o trabalho com as variáveis dos dados dos três Censos. Oito variáveis foram utilizadas, criadas e/ou padronizadas para formulação desse estudo: quatro relacionadas ao chefe do domicílio (Sexo, Cor, Faixa Etária, Grau do último curso frequentado); uma referente à faixa salarial domiciliar; uma referente às sub-bacias do SISAR (define em qual das oito sub-bacias do SISAR, apresentadas na Figura 1, o domicílio se encontra); duas referentes às formas de abastecimento de água: "Abastec" (diz respeito à maneira que determinada residência tem acesso a água) e "Abastec1" (informa se a residência é atendida por rede de abastecimento de água ou não).

Criaram-se, no SPSS, análises de frequência para a variável "Abastec", com o intuito de caracterizar o histórico das formas de acesso à água. Formulou-se ainda uma estatística descritiva do tipo "Tabela de Referência Cruzada", em que a variável "Abastec" foi cruzada com a variável "SISAR". Ainda no SPSS, e com auxílio da variável "Abastec1", realizou-se a Regressão Logística Binária, sendo essa a variável dependente enquanto outras seis representam as covariáveis ("Sexo", "Cor", "Faixa Salarial Domiciliar”, "Faixa Etária”, "Grau do Último Curso Frequentado pelo Chefe" e "SISAR").

Em relação à Regressão Logística Binária, a mesma apresenta variável dependente com resposta binária - nesse caso a existência, ou não, de rede de abastecimento -, que se relaciona com as variáveis aleatórias categóricas supracitadas. Nessa apreciação, trabalha-se com as chances de um determinado grupo apresentar rede de abastecimento de água em relação ao seu grupo de referência. No caso da Tabela 3, essa chance é expressa pela coluna "Exp (B)"; quando esse valor é, por exemplo, 1.479, isso significa que determinado grupo apresenta $47,9 \%$ a mais de chance de ter acesso à rede de abastecimento do que seu grupo de referência. Na maioria dos casos, o grupo de referência escolhido foi aquele em que a chance de encontrar água proveniente de rede era menor. Com relação à significância estatística, adotou-se um valor de $5 \%$.

Quando se quer estudar a probabilidade P da presença de saneamento no domicílio, não se modela o P, mas o seu logit. Isso ocorre porque P varia entre 0 e 1 , o que incorre em uma restrição que impossibilita a interpretação dos resultados. Como o log de $\mathrm{P}$ e 1-P está entre - $-\infty$ e ${ }^{\infty}$, pode-se interpretar a presença do saneamento em termos de razões de chance (odds ratio), representada pelo logaritmo do quociente de $P /(1-P)$, o que elimina a restrição anterior. A odds ratio da presença do saneamento pode ser descrita conforme a Equação 1 (HOSMER \& LEMESHOW, 2000):

Odds ratio $=\frac{P(Y=j \mid z+1) / P(Y=k \mid z+1)}{P(Y=j \mid z) / P(Y=k \mid z)}$

(Equação1) 
A interpretação das razões de chance é obtida a partir dos logs para $\mathrm{J}^{-1}$ razões de probabilidades, $\ln ($ Pij/Pik $)=\beta^{\prime}$ jzi, para j=2,..., -1 .

A partir do modelo logístico binário é possível verificar os efeitos puros de variáveis demográficas, socioeconômicas, regionais e de gestão sobre a presença de redes de água nos domicílios, mensurando-se a razão das chances de presença dessas redes em domicílios com características bem definidas. Os achados relativos a essa análise podem trazer evidências sobre a melhor estratégia a ser seguida com o intuito de alcançar a universalização do acesso.

A respeito dos dados fornecidos pelo SISAR, o banco de dados encontrava-se em arquivos de Excel. Foi necessária a normalização e o ajuste das tabelas, a produção dos gráficos e a análise dos resultados. Foi indispensável a divisão dos municípios de acordo com sua localização geográfica nas sub-bacias do Programa; tal divisão foi feita com utilização do software ArcGIS.

\section{RESULTADOS E DISCUSSÕES}

Inicialmente foram analisadas as informações provenientes do banco de dados do SISAR. As Figuras 3, 4 e 5 representam a evolução do programa, desde 1996, quando foi criado, até 2014, sendo que os dados de 2014 foram computados até o mês de outubro. A partir dos elementos acerca das localidades filiadas, pessoas atendidas e total de ligações à rede, pôde-se caracterizar a atuação histórica do SISAR na região.

Figura 3: Série Histórica do Total de Localidades Filiadas ao SISAR - CE segundo as regiões administrativas do Programa

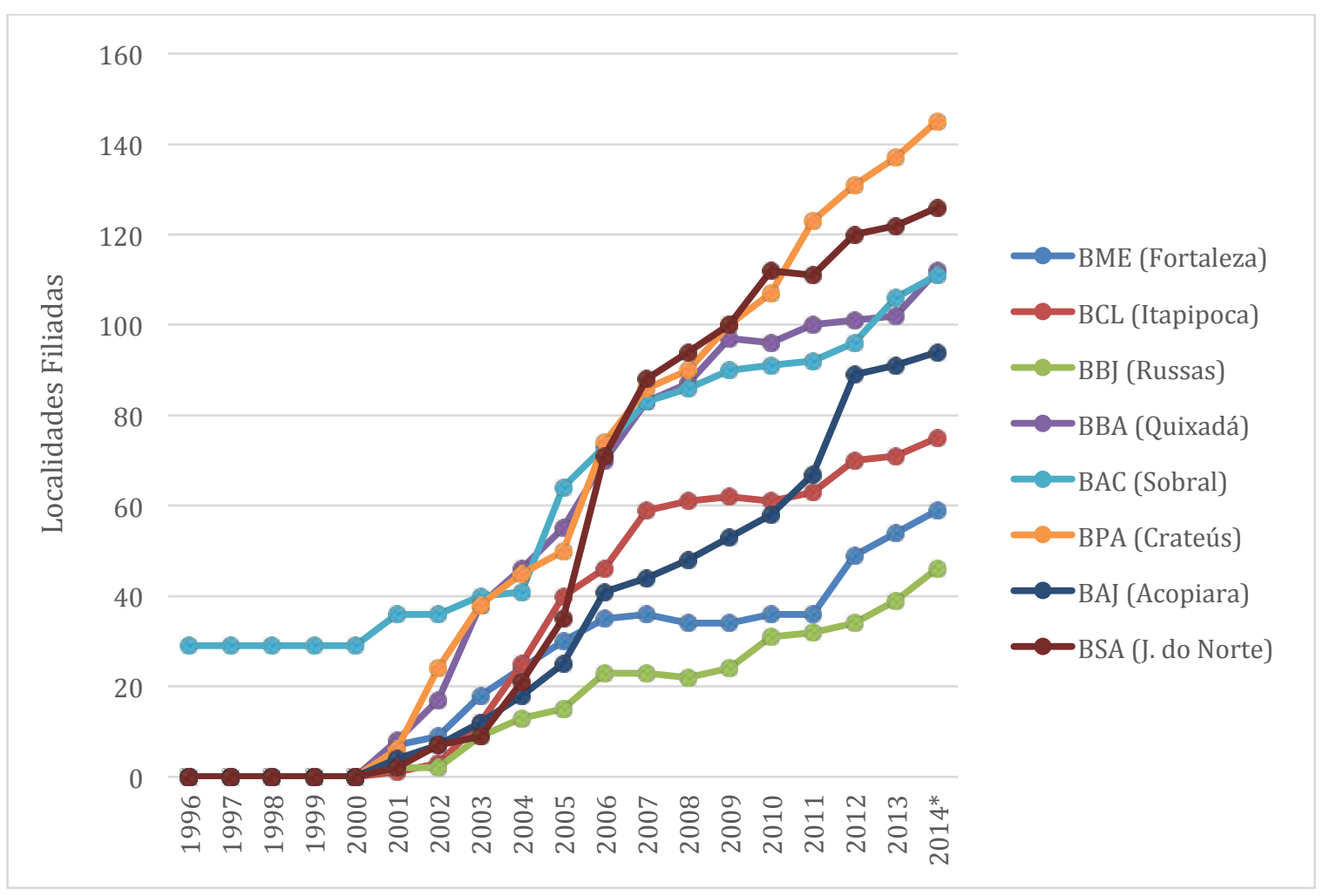

Fonte dos dados básicos: SISAR (2014) 
Figura 4: Série Histórica do Total de Pessoas Atendidas pelo SISAR - CE segundo as regiões administrativas do Programa

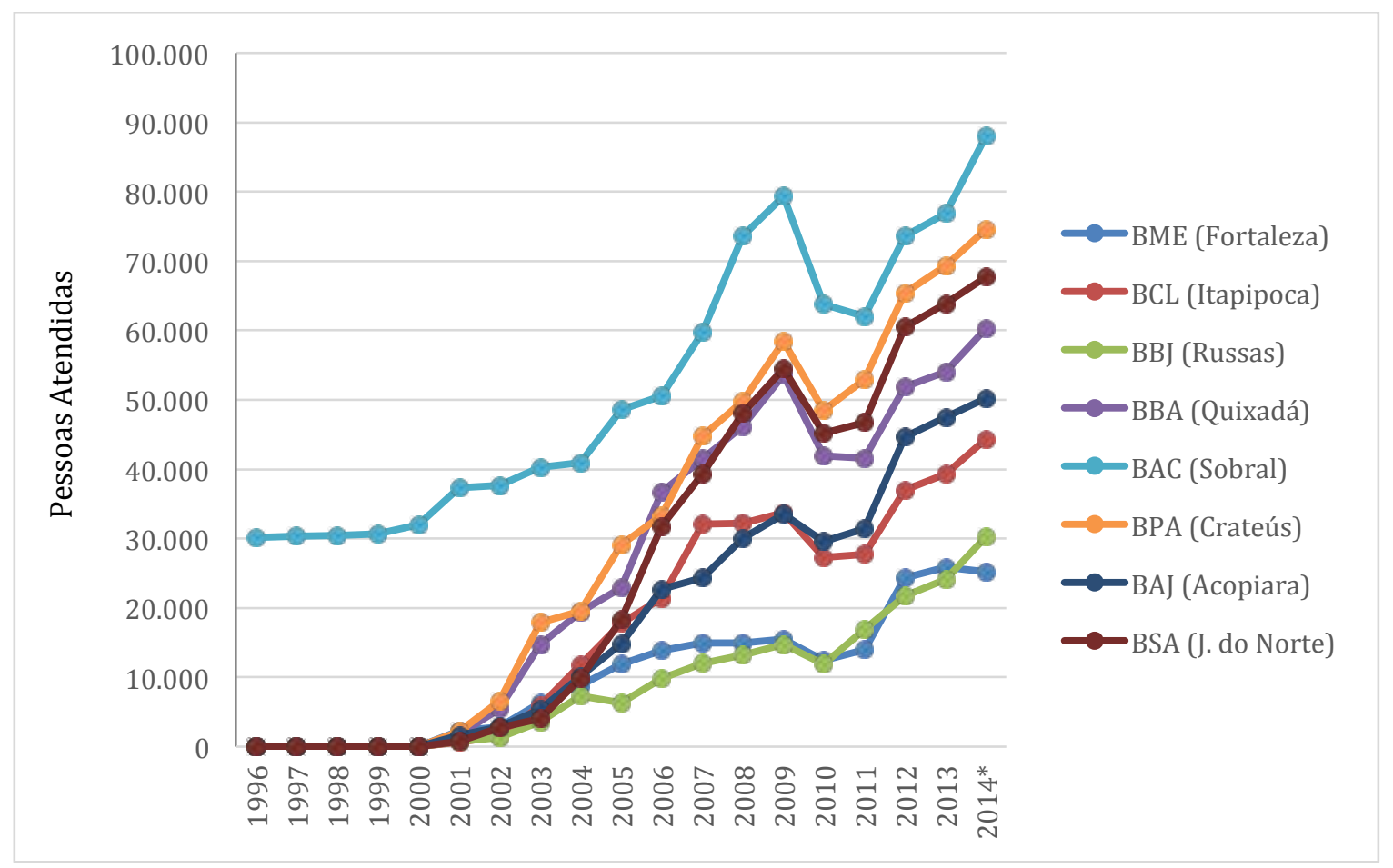

Fonte dos dados básicos: SISAR (2014)

Figura 5: Série Histórica do Total de Ligações de Rede do SISAR - CE segundo as regiões administrativas do Programa

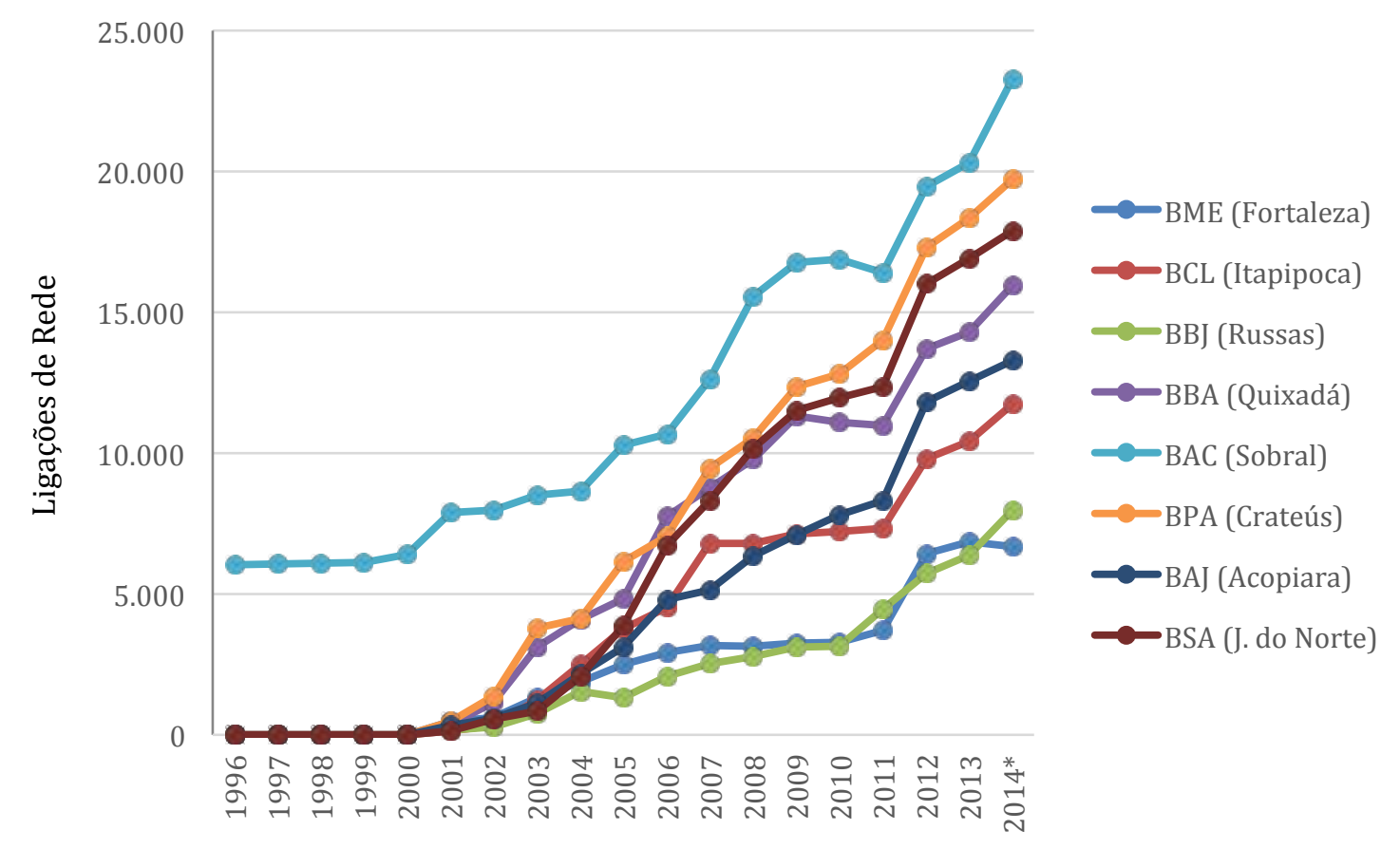

Fonte dos dados básicos: SISAR (2014) 
Até 2001, o único SISAR em atividade era o da região de Sobral. Tal fato explica a tendência que essa sub-bacia apresenta de liderar os indicadores representados nas Figuras 4 e 5, em 2014. Na atualidade, o SISAR Sobral é o único que não necessita de auxílio financeiro externo.

O SISAR Crateús ocupava, em 2014, a primeira posição no número de localidades filadas ao Programa. Sendo assim, infere-se que maiores investimentos tanto em infraestrutura como em gestão foram recebidos por essa região. Percebe-se também que o crescimento foi gradual nos três parâmetros avaliados, o que leva à conclusão de que os investimentos foram constantes. O Programa na sub-bacia de Quixadá apresenta comportamento semelhante ao de Crateús, com um crescimento aproximadamente constante nos três aspectos avaliados, tendo estado, em 2014, em terceiro lugar em número de localidades filiadas, e em quarto, nos outros dois aspectos representados pelas Figuras 4 e 5.

O SISAR de Juazeiro do Norte apresenta um comportamento diferente. Até 2005 ele estava entre os últimos colocados em todos os quesitos, quando passou a apresentar crescimento acelerado em seu desempenho - principalmente no número de localidades atendidas. Em 2014, esse SISAR assumiu a segunda posição no número de localidades atendidas e terceiro nas demais. Pode-se inferir que, a partir de 2006, maiores investimentos fo- ram realizados nessa localidade, o que levou a um célere avanço do programa na região.

Os sistemas das demais sub-bacias - Acopiara, Fortaleza, Itapipoca e Russas - apresentaram desempenhos mais modestos. Conclui-se que, nessas localidades, o investimento e/ou a adesão dos municípios ao SISAR foi menor. Isso, contudo, não caracteriza, por si só, que os índices de cobertura por rede de abastecimento de água nessas regiões sejam inferiores, apenas que o SISAR estava menos presente nessas regiões. Como ver-se-á a seguir, a sub-bacia de Russas apresenta bons índices de cobertura por rede de abastecimento.

$\mathrm{Na}$ Figura 6 apresenta-se o total de pessoas atendidas pelo SISAR nas regiões rurais do Ceará.

Percebe-se que até o ano 2000 o número de pessoas atendidas permaneceu constante. Com a expansão do Programa para outras sub-bacias do Ceará, o número de pessoas atendidas cresceu em ritmo bastante acelerado até 2009, quando apresentou uma queda. Tal evolução anômala ocorre tendo em vista que a população atendida é estimada por meio da Pesquisa Nacional por Amostra de Domicílios (PNAD). Com a ocorrência do Censo 2010, constatou-se uma superestimava do número de pessoas atendidas pelo Programa. Esse erro pode causar falhas na alocação de recursos e mascarar a real situação do abastecimento de água nas áreas rurais do Estado. 
Figura 6: Série Histórica do Total de Pessoas Atendidas pelo SISAR no Estado do Ceará

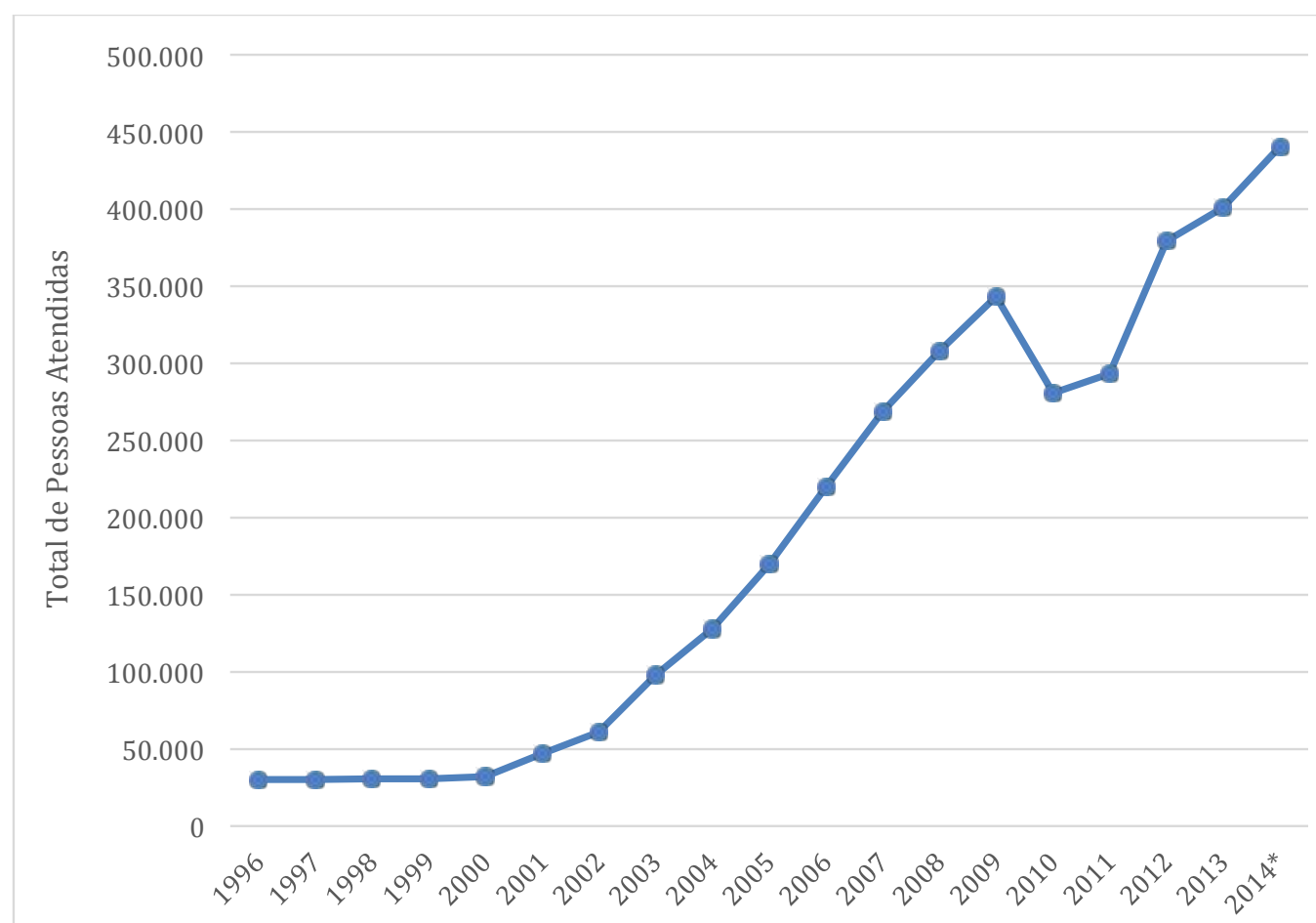

Fonte dos dados básicos: SISAR (2014)

Considerando informações referentes ao ano de 2010, das 2.106.347 pessoas existentes na área rural do Ceará, 280.710 eram atendidas pelo SISAR, representando um total de aproximadamente $14 \%$ da população rural daquele Estado (IBGE, 2012; SISAR 2014).

Avaliando-se dados do ano de 2014, percebe-se que a grande maioria dos municípios do Ceará contava com a presença do Programa. Isso é muito importante, pois prova que o SISAR tem o intuito de estar presente na maior parte das localidades rurais do Estado. Tem-se a presença do Programa em 137 dos 184 municípios do Estado.
Esse número totaliza 74\% dos municípios cearenses (SISAR 2014).

A Figura 7 demonstra a divisão desses 137 municípios atendidos pelos SISAR. Percebe-se que as sub-bacias com o maior número de municipalidades filiadas - Sobral (24), Juazeiro do Norte (20), Quixadá (19) e Crateús (17) - coincidem com as maiores em números de localidades atendidas (Figura 3). Ao olhar pelo outro extremo, as duas bacias com menor número de municípios participantes do Programa SISAR coincidem com os menores números de localidades atendidas. Isso corrobora a confiabilidade de ambas fontes de dados. 
Figura 7: Municípios atendidos pelo SISAR divididos por sub-bacias

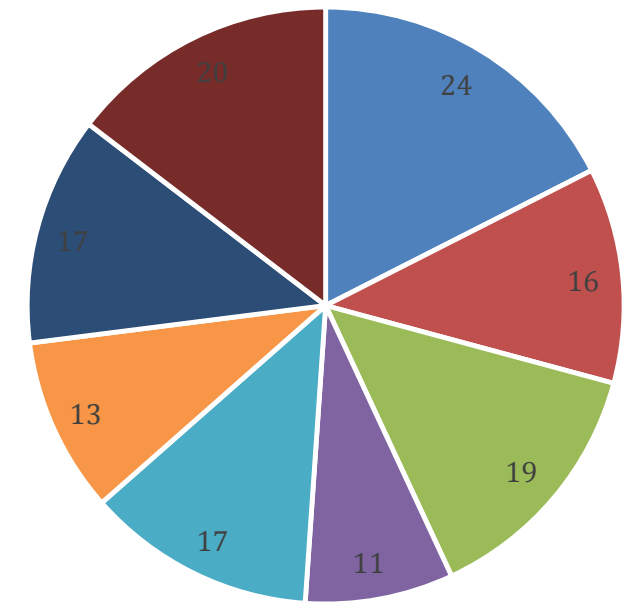

\author{
- Responsável: SISAR Sobral. \\ - Responsável: SISAR Acopiara. \\ - Responsável: SISAR Quixadá. \\ - Responsável: SISAR Russas. \\ - Responsável: SISAR \\ Itapipoca. \\ - Responsável: SISAR \\ Fortaleza. \\ - Responsável: SISAR Crateús. \\ - Responsável: SISAR Juazeiro.
}

Fonte dos dados básicos: SISAR (2014)

Os dados dos Censos Demográficos de 1991, 2000 e 2010, apresentados na Tabela 1, caracterizam a evolução das seis formas de obtenção de água nos domicílios rurais no Ceará.

Tabela 1: Formas de obtenção de água nos domicílios rurais do Ceará

\begin{tabular}{|l|c|c|c|}
\hline \multirow{2}{*}{ Tipo } & \multicolumn{3}{|c|}{ Ano } \\
\cline { 2 - 4 } $\begin{array}{l}\text { Rede geral com canalização } \\
\text { interna }\end{array}$ & 1991 & $\mathbf{2 0 0 0}$ & $\mathbf{2 0 1 0}$ \\
\hline $\begin{array}{l}\text { Poço ou nascente com } \\
\text { canalização interna }\end{array}$ & $1,63 \%$ & $5,10 \%$ & $27,28 \%$ \\
\hline $\begin{array}{l}\text { Outra forma com canalização } \\
\text { interna }\end{array}$ & $0,54 \%$ & $1,75 \%$ & $4,63 \%$ \\
\hline $\begin{array}{l}\text { Rede geral sem canalização } \\
\text { interna }\end{array}$ & $0,47 \%$ & $3,23 \%$ & $5,90 \%$ \\
\hline $\begin{array}{l}\text { Poço ou nascente sem } \\
\text { canalização interna }\end{array}$ & $27,72 \%$ & $41,84 \%$ & $24,67 \%$ \\
\hline $\begin{array}{l}\text { Outra forma sem } \\
\text { canalização interna }\end{array}$ & $68,34 \%$ & $41,27 \%$ & $21,77 \%$ \\
\hline
\end{tabular}

Fonte dos dados básicos: IBGE (1993, 2002, 2012)
Na análise da Tabela 1 trabalhou-se com seis diferentes formas de aquisição do recurso natural: rede geral, poço ou nascente e outras formas, todas as três podendo ser-ou não-com canalização interna.

A ocorrência de canalização no interior das residências é característica ligada à conscientização da população sobre a importância dessa presença e também ao nível socioeconômico da mesma. Por um lado, percebe-se a essencialidade de acessar a água mais facilmente e em quantidade suficiente para a ingestão e a higiene; por outro, a existência da canalização interna na residência eleva o consumo da água - historicamente tida como um bem escasso nessas regiões -, implicando na elevação do consumo e, consequentemente, do custo da mesma.

Interessante observar que no ano de 1991 a obtenção de água por meio de rede geral, no Ceará, totalizava apenas $1,56 \%$ dos domicílios da área rural, uma quantia pouco significativa, que representava apenas 6.575 residências. Em 2010, esse valor sobe para 184.818 domicílios, número que 
representa 33,17\% do total (IBGE, 2012). É inegável a influência do SISAR nas regiões rurais do Estado, sendo a evolução positiva dos dados clara. $O$ número de domicílios com acesso à rede aumenta, e a quantidade dependente de outras formas de acesso diminui.

Outras formas de acesso à água (longas caminhadas até açudes, caminhões pipa, bicas e chafarizes etc.), sem rede no interior dos domicílios, têm uma queda vertiginosa a partir de 1991: de 68,34\%, passam a representar 21,77\% em 2010. Esse avanço é um dos mais importantes, tendo em vista que essas outras formas de obtenção do recurso são as mais penosas para os usuários, principalmente as mulheres, que na maioria das vezes são responsáveis pela aquisição da água quando esta se dá fora do domicílio (LAVINAS et al., 2012).

Em 2000, observa-se um aumento na modalidade poço ou nascente sem canalização interna $(41,84 \%)$; contudo, em 2010 esse número se torna menor do que em 1991 (24,67\%). Infere-se que, em um primeiro momento - entre 1991 e 2000 -, uma parte dos domicílios migrou de outras formas de acesso a água, sem canalização interna, para poço ou nascente, sem canalização interna. Em um segundo momento, ocasião de expansão do SISAR para todo Ceará, esses domicílios tornaram-se, em grande medida, usuários da rede geral de abastecimento.

Olhando pelo viés da ocorrência de canalização interna, pode-se perceber um aumento em todas as formas de abastecimento (rede geral, poço ou nascente e outras formas). Infere-se que esse fato se deva, principalmente, à conscientização das populações acerca da importância de um acesso facilitado ao recurso, bem como aos avanços socioeconômicos da região.

A mudança mais drástica ocorre justamente nas formas de acesso ligadas ao SISAR: presença de rede, com canalização interna ou externa. A Figura 8 demonstra essa mudança.

Figura 8: Série Histórica - Presença de rede de abastecimento de água com e sem canalização interna

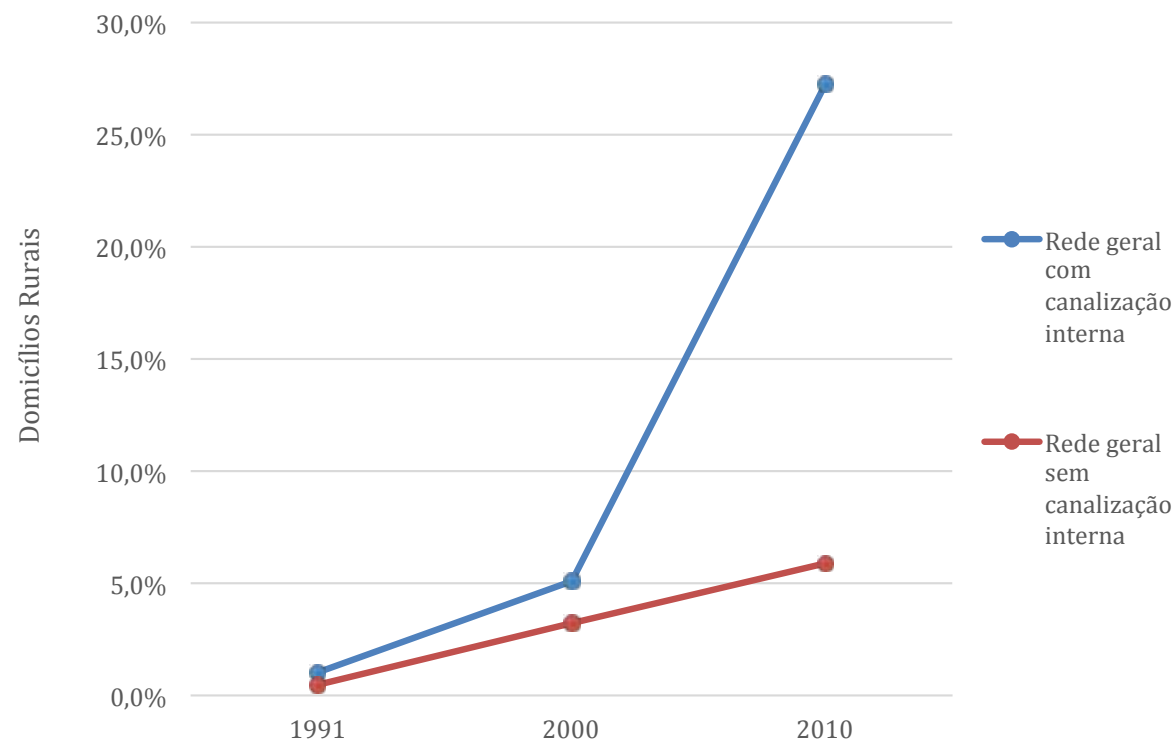

Fonte dos dados básicos: IBGE $(1993,2002,2012)$ 
A estrutura das curvas da Figura 8 é forte evidência da atividade do SISAR. Em 1991, 4.522 residências estavam ligadas à rede geral com canalização interna e 2.053 sem canalização interna; em 2010, 151.969 habitações contavam com rede de água com canalização interna - um aumento de mais de $7400 \%$ - e 32.849 sem canalização interna - um acréscimo de mais de 720\% (IBGE 1993, 2002 e 2012).

Todos os destaques citados demonstram que o SISAR realmente melhorou as formas de acesso à água da população rural do Ceará. Contudo, a evidência mais contundente da atuação do Programa ocorre ao avaliar a evolução da série histórica da presença de rede com canalização interna. De 1991 para 2000 ocorre um aumento de representatividade dessa modalidade de 1,03\% para 5,10\%. Já de 2000 para 2010, o valor sobe para 27,27\% (IBGE 1993, 2002 e 2012). Conclui-se que o SISAR tenha sido fundamental para esse salto no atendimento.

O foco principal do SISAR é levar as redes de abastecimento de água até as residências. Sendo assim, nas análises seguintes usar-se-á a variável presença de rede de abastecimento de água, independentemente de ela ser ou não interna.

A Tabela 2 expõe dados referentes à localização dos municípios, de acordo com a divisão do SISAR, e à presença de rede de abastecimento nos domicílios. Há a inclusão de municípios nos quais está ou não presente o Programa SISAR. É importante salientar que nas Tabelas 1 e 2 as porcentagens são referentes apenas aos domicílios rurais do Estado do Ceará.

Tabela 2: Presença de rede nos domicílios rurais do Ceará x sub-bacia hidrográfica do SISAR

\begin{tabular}{|l|c|c|c|c|c|c|c|}
\hline \multirow{2}{*}{ Bacia do SISAR } & \multicolumn{9}{|c|}{ Ano } \\
\cline { 2 - 9 } & Percentagem & $\begin{array}{c}\text { Valor } \\
\text { Absoluto }\end{array}$ & Percentagem & $\begin{array}{c}\text { Valor } \\
\text { Absoluto }\end{array}$ & Percentagem & $\begin{array}{c}\text { Valor } \\
\text { Absoluto }\end{array}$ \\
\hline Acopiara & $0,19 \%$ & 854 & $1,21 \%$ & 5594 & $3,83 \%$ & 21273 \\
\hline Crateús & $0,05 \%$ & 201 & $0,62 \%$ & 2877 & $4,97 \%$ & 27601 \\
\hline Fortaleza & $0,11 \%$ & 484 & $0,69 \%$ & 3185 & $2,91 \%$ & 16195 \\
\hline Itapipoca & $0,25 \%$ & 1079 & $0,77 \%$ & 3579 & $3,17 \%$ & 17592 \\
\hline J. do Norte & $0,32 \%$ & 1388 & $1,38 \%$ & 6384 & $3,98 \%$ & 22135 \\
\hline Quixadán & $0,20 \%$ & 862 & $0,70 \%$ & 3248 & $5,19 \%$ & 28853 \\
\hline Russas & $0,28 \%$ & 1225 & $1,90 \%$ & 9029 & $4,60 \%$ & 25788 \\
\hline Sobral & $0,11 \%$ & 482 & $1,00 \%$ & 4856 & $4,60 \%$ & 25380 \\
\hline
\end{tabular}

Fonte dos dados básicos: IBGE (1993, 2002, 2012)

Relacionando os dados dos Censos Demográficos com os dados fornecidos pelo SISAR, e expostos nas Figuras 3 , 4 e 5, chega-se a observações importantes.

Com exceção da região de Russas, sobre a qual se comentará a seguir, as regiões que apresentam os melhores desempenhos no quesito presença de rede de abastecimento - Sobral, Crateús, Quixadá - são as mesmas que estão melhores posicionadas nos quesitos anteriormente analisados, segundo dados do SISAR (total de localidades filiadas, total de ligações e total de pessoas atendidas). As de pior desempenho - Itapipoca e Fortaleza - são justamente as que apresentam menores investimentos e presença do Programa SISAR em seus municípios.

No caso de Russas, infere-se que o percentual de presença de rede de abastecimento de água se deva a outros programas e ações de saneamento, além do SISAR. Como demonstrado, a presença do Programa na bacia, apesar de ser uma realidade, não é considerada uma das mais marcantes.

O que se percebe é que, apesar de todas as bacias apresentarem elevação nas taxas de crescimento 
do atendimento por rede de água no período a partir de 2001, nos SISAR de Crateús, Sobral e Quixadá ocorre uma admirável ampliação. Isso vem mais uma vez corroborar a influência do Programa, principalmente nessas três bacias que se revelam como as mais consolidadas.
Apresenta-se na Tabela 3 a análise de Regressão Logística Binária para seis covariáveis, tendo como variável dependente a presença, ou não, de rede de abastecimento de água nos domicílios rurais do Estado do Ceará.

Tabela 3: Resultados obtidos com a análise de regressão logística binária para a variável resposta presença de rede de abastecimento de água.

\begin{tabular}{|c|c|c|c|c|c|c|}
\hline \multicolumn{2}{|c|}{$\begin{array}{l}\text { Caracterização da variável } \\
\text { (A categoria de referência } \\
\text { encontra-se na primeira linha) }\end{array}$} & \multirow[t]{2}{*}{ B } & \multirow[t]{2}{*}{$\begin{array}{l}\text { Desvio } \\
\text { Padrão }\end{array}$} & \multirow{2}{*}{$\begin{array}{c}\text { Graus de } \\
\text { liberdade } \\
4\end{array}$} & \multirow{2}{*}{$\begin{array}{c}\text { Significância } \\
0,000\end{array}$} & \multirow[t]{2}{*}{$\operatorname{Exp}(B)$} \\
\hline \multirow{5}{*}{$\begin{array}{l}\text { Cor da pele do } \\
\text { responsável pelo } \\
\text { domicílio }\end{array}$} & Preta & & & & & \\
\hline & Indígena & $-0,177$ & 0,209 & 1 & 0,399 & 0,838 \\
\hline & Amarela & 0,089 & 0,102 & 1 & 0,386 & 1,093 \\
\hline & Parda & 0,162 & 0,045 & 1 & 0,000 & 1,176 \\
\hline & Branca & 0,233 & 0,047 & 1 & 0,000 & 1,263 \\
\hline \multirow{5}{*}{$\begin{array}{l}\text { Grau do último } \\
\text { curso frequentado } \\
\text { pelo chefe do } \\
\text { domicílio }\end{array}$} & $\begin{array}{l}\text { Alfabetização } \\
\text { e } \\
\text { Alfabetização } \\
\text { de adultos }\end{array}$ & & & 4 & 0,000 & \\
\hline & $1^{\circ} \mathrm{grau}$ & 0,197 & 0,028 & 1 & 0,000 & 1,218 \\
\hline & $2^{\circ} \mathrm{grau}$ & 0,648 & 0,040 & 1 & 0,000 & 1,913 \\
\hline & Superior & 0,426 & 0,095 & 1 & 0,000 & 1,532 \\
\hline & $\begin{array}{c}\text { Pós- } \\
\text { graduação }\end{array}$ & 0,427 & 0,198 & 1 & 0,031 & 1,532 \\
\hline \multirow{4}{*}{$\begin{array}{l}\text { Renda agregada } \\
\text { domiciliar (em } \\
\text { salários mínimos) }\end{array}$} & Até 1 & & & 3 & 0,000 & \\
\hline & 1 até 3 & 0,308 & 0,022 & 1 & 0,000 & 1,361 \\
\hline & 3 até 5 & 0,561 & 0,043 & 1 & 0,000 & 1,752 \\
\hline & Acima de 5 & 0,538 & 0,070 & 1 & 0,000 & 1,712 \\
\hline \multirow{15}{*}{$\begin{array}{l}\text { Grupo etário } \\
\text { quinquenal do } \\
\text { responsável pelo } \\
\text { domicílio }\end{array}$} & 15 a 19 & & & 14 & 0,000 & \\
\hline & 10 a 14 & 0,167 & 0,575 & 1 & 0,771 & 1,182 \\
\hline & 20 a 24 & 0,112 & 0,112 & 1 & 0,316 & 1,119 \\
\hline & 25 a 29 & 0,352 & 0,108 & 1 & 0,001 & 1,422 \\
\hline & 30 a 34 & 0,446 & 0,108 & 1 & 0,000 & 1,563 \\
\hline & 35 a 39 & 0,525 & 0,108 & 1 & 0,000 & 1,690 \\
\hline & 40 a 44 & 0,425 & 0,108 & 1 & 0,000 & 1,529 \\
\hline & 45 a 49 & 0,416 & 0,108 & 1 & 0,000 & 1,516 \\
\hline & 50 a 54 & 0,389 & 0,109 & 1 & 0,000 & 1,475 \\
\hline & 55 a 59 & 0,475 & 0,110 & 1 & 0,000 & 1,608 \\
\hline & 60 a 64 & 0,374 & 0,112 & 1 & 0,001 & 1,454 \\
\hline & 65 a 69 & 0,353 & 0,114 & 1 & 0,002 & 1,423 \\
\hline & 70 a 74 & 0,416 & 0,115 & 1 & 0,000 & 1,516 \\
\hline & 75 a 79 & 0,384 & 0,121 & 1 & 0,002 & 1,468 \\
\hline & 80 anos e mais & 0,462 & 0,120 & 1 & 0,000 & 1,588 \\
\hline \multirow{2}{*}{$\begin{array}{l}\text { Sexo do responsável } \\
\text { pelo domicílio }\end{array}$} & Masculino & & & & 0,000 & \\
\hline & Feminino & 0,185 & 0,022 & 1 & 0,000 & 1,203 \\
\hline \multirow{8}{*}{$\begin{array}{l}\text { Localização do } \\
\text { domicílio segundo } \\
\text { a região de } \\
\text { abrangência do } \\
\text { SISAR }\end{array}$} & Itapipoca & & & 7 & 0,000 & \\
\hline & Fortaleza & 0,058 & 0,044 & 1 & 0,189 & 1,060 \\
\hline & J. do Norte & 0,248 & 0,042 & 1 & 0,000 & 1,282 \\
\hline & Acopiara & 0,303 & 0,043 & 1 & 0,000 & 1,353 \\
\hline & Quixadá & 0,349 & 0,040 & 1 & 0,000 & 1,418 \\
\hline & Sobral & 0,375 & 0,040 & 1 & 0,000 & 1,456 \\
\hline & Crateús & 0,774 & 0,041 & 1 & 0,000 & 2,168 \\
\hline & Russas & 1,062 & 0,041 & 1 & 0,000 & 2,891 \\
\hline
\end{tabular}


A análise da Tabela 3 revela as chances de a cor da pele do responsável pela habitação ser fator de influência no acesso à rede de abastecimento. Duas das categorias não são significativas (indígena e amarela). Em relação às demais categorias da variável "Cor", observa-se que a chance de um domicílio chefiado por uma pessoa de cor branca ter rede de abastecimento de água é $26,30 \%$ maior do que a de um domicílio com chefe de cor preta. A chance de um domicílio chefiado por uma pessoa de cor parda ter rede de abastecimento de água é $18,00 \%$ maior do que a de um chefe de cor preta. Tal resultado já era esperado, uma vez que há uma relação notória entre as condições de vida e a cor da pele dos indivíduos (VASCONCELOS, 2005).

No que diz respeito à variável "Grau do último curso frequentado pelo chefe do domicílio", todas as categorias mostraram-se significativas. A análise revela um aumento expressivo das chances de os domicílios terem acesso à rede de água quando o chefe do domicílio frequentou o segundo grau. Nos casos em que o chefe frequentou nível superior ou pós-graduação há cerca de $50 \%$ a mais de chance de os domicílios acessarem rede de distribuição de água em relação à categoria de referência.

Para a variável "Renda agregada domiciliar", percebe-se a correlação positiva entre o seu crescimento e o aumento das chances de presença de redes de água nos domicílios. Os domicílios que possuem renda de um a três salários mínimos apresentam $36,10 \%$ a mais de chances de terem acesso à rede de abastecimento do que os que possuem renda de até um salário mínimo. Os que possuem renda agregada acima de cinco salários mínimos têm $71,20 \%$ a mais de chances de presença de rede de água domiciliar que a categoria de referência.

Não se encontrou relação clara entre o aumento da idade e as chances de os domicílios terem acesso à rede de abastecimento de água. Têm-se ainda que alguns grupos etários mais jovens não se mostraram significativos (de 10 a 14 e de 20 a 24 anos). Nas faixas etárias significativas, observamse maiores chances de acesso à rede (essas variam de $42,00 \%$ até $69,00 \%$ ) com relação à categoria de referência (de 15 a 19 anos). Ainda assim, não há tendência clara em relação ao crescimento da presença das redes domiciliares de água com o aumento da idade do chefe.

Foi comprovada na análise uma maior chance de os domicílios chefiados por mulheres obterem água por meio de rede de distribuição. As chances são $20,30 \%$ maiores com relação a habitações chefiadas por homens.

Bastante interessante são os resultados obtidos para a variável "Localização do domicílio segundo região de abrangência do SISAR", pois essas mostraram chances significativamente maiores de presença de redes de abastecimento de água nas regiões nas quais o SISAR se encontra melhor consolidado.

Percebe-se, mais uma vez, a sub-bacia de "Russas" como um caso à parte. Essa apresenta as maiores chances de acesso à rede de distribuição de água em seus domicílios; contudo, a presença do SISAR nessa região é uma das menos relevantes - vide Figuras 3 , 4 e 5 .

Como grupo de referência tem-se "Itapipoca". Essa bacia encontra-se entre as que menos receberam influência e investimentos do SISAR - assim como "Fortaleza", que possui apenas $6,00 \%$ de chances a mais de apresentar rede com relação à referência. Apesar disso, "Fortaleza" não se mostra significativa.

É evidente o impacto do Programa no acesso à rede nos domicílios das sub-bacias. As três regiões com maior presença do SISAR ("Sobral”, "Quixadá" e "Crateús") são também, com exceção de "Russas", as que apresentam maiores chances de presença de rede com relação a "Itapipoca". Conclui-se, assim, que há eficiência no Sistema SISAR no que se propõe: expandir o atendimento por redes de água nos domicílios rurais do Ceará. 


\section{CONCLUSÕES}

A presente pesquisa propôs encontrar evidências de que a presença do Sistema Integrado de Saneamento Rural alterou, positivamente, a relação dos domicílios em relação ao acesso às redes de abastecimento de água.

O objetivo foi concretizado. Por meio da revisão bibliográfica e dos dados provenientes do SISAR e do Censo Demográfico do IBGE, foi possível caracterizar o saneamento rural do Estado - no que se refere à água - e criar um histórico do mesmo. Comprovase que houve uma grande melhoria nas formas de aquisição de água na região desde 1991.

Fica evidente o papel importante e positivo do SISAR. É clara a evolução dos índices provenientes da implantação e expansão do programa. Apesar de ainda necessitar de aperfeiçoamento, acredita-se que o SISAR é um exemplo que pode ser adotado em outras regiões rurais do País.

Como indicação de estudos futuros, que podem se originar desse trabalho, cita-se: examinar o caso da Bacia Hidrográfica de Russas, que apesar de pouca presença do SISAR apresenta altos índices de acesso à rede de distribuição de água; caracterizar o estado do Ceará visando particularidades referentes à coleta e tratamento de esgotos e à gestão de resíduos sólidos.

\section{REFERÊNCIAS}

CRUZ, B. A. et al. Avaliação do Sistema Integrado de Saneamento Rural do Ceará (SISAR/CE) a partir da concepção de inovação sociotécnica. In: $1^{\circ}$ CONGRESO INTERAMERICANO DE AGUA POTABLE YSANEAMIENTO RURAL, AIDIS, CUENCA. Anais... Cuenca, 2014.

HOCHMAN, G. A era do saneamento: As bases da política de saúde pública no Brasil. São Paulo: Hucitec/Anpocs, 1998.
HOSMER, D. W.; LEMESHOW, S. Applied Logistic Regression. Nova Iorque: John Wiley \& Sons, 2000, $2^{\mathrm{a}}$.ed..

IBGE. Censo Demográfico de 2010: resultados do universo. Rio de Janeiro: IBGE, 2012.

IBGE. Censo Demográfico de 2000: resultados do universo. Rio de Janeiro: IBGE, 2002.

IBGE. Censo Demográfico de 1991: resultados do universo. Rio de Janeiro: IBGE, 1993.

LAVINAS, L.; COBO, B.; VEIGA, A. Bolsa Família: impacto das transferências de renda sobre a autonomia das mulheres pobres e as relações de gênero. Revista Latinoamericana de Población, 10 (6), 31-56, 2012.

MELEG, A. SISAR: A sustainable management model for small rural decentralized water and wastewater systems in developing countries. Journal of Water, Sanitation and Hygiene for Development, 2(4), 291-300, 2012.

NARAYAN, D. Empowerment and poverty reduction: a sourcebook. Washington: The World Bank, 2002.

PRINCE, A. Análise de experiências relevantes e sustentáveis na elaboração, implementação e gestão de projetos e serviços de saneamento básico em localidades urbanas de pequeno porte em áreas rurais no Brasil. A experiência do Estado do Ceará. Brasília: SEPURB, 1999.

REZENDE, S.C.; HELLER, L. 0 saneamento no Brasil: políticas e interfaces. Belo Horizonte: Editora UFMG, 2008, $2^{\mathrm{a}}$.ed.

REZENDE, S.C. et al. Análise do Serviço Integrado de Saneamento Rural - SISAR, do Ceará, em sua dimensão político-institucional. FUNASA. Belo Horizonte, 2014. Relatório.

SCHWEIZER, L. T.; NIERADTKA, K. "Publicização”, uma alternativa aos extremos da privatização e da estatização: um estudo de caso do SISAR, no setor de água e saneamento. Revista de Administração Pública. 35(2), 153-191, 2001.

SISAR. Dados operacionais do período de 1995 até 2014. Fortaleza: SISAR, 2014.

SPINK, P. Controle Social das Ações Públicas: SISAR - Ceará. In: XI COLÓOUIO INTERNACIONAL SOBRE PODER LOCAL: DESENVOLVIMENTO E GESTÃO DE TERRITÓRIOS. Universidade Federal da Bahia, Salvador, BA. Anais... Salvador, 2009.

VASCONCELOS, L. Sociedade - Realidade em preto e branco. Desafios do Desenvolvimento. 17 (2), 1-8, 2005. 